\title{
The effect of a role-playing exercise on clerkship students' views of death notification: the Swedish experience
}

\author{
Anna Nordström ${ }^{1}$, Anncristine Fjellman-Wiklund², Tomas Grysell ${ }^{3}$ \\ ${ }^{1}$ Department of Community Medicine and Rehabilitation, Geriatric Medicine, Umeå University, Sweden \\ ${ }^{2}$ Department of Community Medicine and Rehabilitation, Physiotherapy, Umeå University, Sweden \\ ${ }^{3}$ Division for Development of Teaching and Learning, Uppsala University, Sweden
}

Correspondence: Anna Nordström, Department of Community Medicine and Rehabilitation, Geriatric Medicine, Umeå University, Sweden. Email: anna.nordstrom@idrott.umu.se

\begin{abstract}
Objectives: The purpose of this study was to examine clerkship students' perspective towards delivering death notifications. An additional purpose of the study was to identify the learning needs of students following a role play exercise in delivering death notifications.

Methods: Participants in this study were fourth-year medical students $(\mathrm{N}=86)$ ranging in age from $22-43$ years with a mean age of 27.1 years. There were 28 women and 58 men. Questionnaires, consisting of open-ended questions and a visual analogue scale (VAS), were administered before and after the "Marathon Death" role play exercise.

Results: Six categories emerged from the analysis of the questionnaire: communication, emotions, selfdevelopment, exercise-related, learning opportunities and tools and strategies. Results from the visual analogue scale showed that the majority of students $(60 \%)$ needed to practice how to deliver difficult messages in death notifica-
\end{abstract}

tions. After taking part in the role-playing activity with video playback, where the students had an opportunity to view, discuss and reenact scenarios, seventy-six out of 78 $(97.4 \%)$ stated that they had received training in communication skills. The responding students rated the exercise as highly relevant, scoring it a mean of 91 on a VAS scale of 0 to $100 \mathrm{~mm}$.

Conclusions: Students are not competent in the communication skills required for delivering death notifications. A majority of students expressed a need for training in communication skills. The "Marathon Death" role play exercise provides initial training and emotional support for delivering a death notification. However, further empirical studies are required about the effect of the exercise on delivering the notification of death.

Keywords: Death notification, role-playing exercises, clerkship students

\section{Introduction}

Communicating bad news is an essential skill for physicians. For example, death notification; informing relatives of the death of a loved one is a disheartening task that is physically and emotionally draining, especially for those without proper training. ${ }^{1-3}$ Death notification not only puts a toll on the informer performing the task, but may also have long-term effects on the grief process of survivors. ${ }^{4}$ Despite the fact that this task is of central importance and has significant implications, less than half of physicians in one study "reported receiving any education during medical school or residency" in death notification, and 94\% reported "a need for education in dealing with death and dying".
The task of learning death notification is complex. A suitable way to learn it could include personally determined experiences and involvement. Experiential learning has been used in different settings within the field of medical education and assumes that people grow and develop as a result of cognitive and social processes. ${ }^{6,7}$ The conceptual basis of the process of experiential learning is commonly related to Kolb's model of the learning cycle, which proposes that learning is best facilitated through acquiring concrete experience and abstract conceptualization, and transforming experience through reflective observation and active experimentation. ${ }^{8}$ As such, a learning process should 
be an active, collaborative and interactive process. To date, very few exercises in death notifications have been evaluated. ${ }^{9-11}$ To address the need for education in death notification for medical students, the Marathon Death, an experiential learning exercise that integrates valuable exercises and socioanalytic role-play, was created at the medical facility at Umeå University in Sweden as a method for illustrating and solving problems in human relations. In our context, it is used to teach and train medical students in delivering death notifications. Marathon Death is influenced by the work of Augusto Boal and his Theatre of the Oppressed. It has been inspirational in the creation of Theatre in Education and experiential learning worldwide and provides opportunities for active, experiential learning. ${ }^{12-14}$ The purpose of this study was to examine clerkship students' perspective towards delivering death notifications. An additional purpose of the study was to identify the learning needs of students following a role-play exercise in delivering death notifications.

\section{Methods}

Our total study cohort included all 86 fourth year students who attended the course entitled "professional development" at Umeå University in Northern Sweden. Of the total students, $67 \%(n=58)$ were women and $33 \%(n=28)$ were men. The course runs through all $51 / 2$ years of the medical school aimed at support medical personal and professional development with an emphasis on the learning of the consultation and the patient-doctor relationship. ${ }^{15}$

The course also addresses challenging patient-doctor communication issues and the students are not informed of the specific exercises within the course in advance.

\section{Ethical Considerations}

The survey was carried out as an evaluation of the Marathon Death exercise and served as a quality assessment of the skills taught in the course entitled "Professional Development". All students who participated in the exercise were informed about the study and the purpose of assessment. Students understood that participation was voluntary and that they could withdraw from participation at any time. A written informed consent was obtained from each student, and anonymity of the students was maintained throughout the study.

\section{Data Collection}

Open- ended questionnaires were designed to identify medical students' attitudes towards delivering death notifications. The students were asked to complete the questionnaires before and after attending the Marathon Death roleplay exercise. The questionnaires were also distributed to all students at the same time by teachers at the course to minimize response bias. Each questionnaire item was carefully formulated to be as clear as possible and the length of the questionnaires was reasonable short so that the respondent could devote a consistent degree of concentra- tion and interest throughout. Furthermore, the questionnaires were administered in conjunction with the exercise to assure that the time frame between the questionnaire and exercise was equal for all and the experience of participation in the exercise were not forgotten. The questionnaires were in Swedish and were translated into English for this article. The translations were discussed by the bilingual translators to detect inconsistencies. The validity of the questionnaires was determined by the three experienced researchers.

\section{Pre-role play questionnaire}

Before attending any exercise, all students were asked to complete a questionnaire covering demographic information and four open-ended questions about death notifications. Seventy-four out of 86 students (86\% response rate) completed the questionnaire, including 51women and 23 men.

\section{The marathon death exercise}

The marathon death exercise includes the identification of underlying principles, indications of good practice, the observation of good and bad practice through video screenings and the exploration of the students' skills in communication and in relaying death notifications. In groups of 8-10, students practiced conveying a death notification. The teacher played the part of next of kin and gave a realistic introduction to the exercise by describing the events leading up to the death of the husband/wife in the most realistic and vivid way possible. Information about the setting was communicated to the students. At the beginning of the exercise, the next of kin would be sitting in the waiting room and waiting on the return of their loved one. The objective of the exercise was for the students to assume the role of doctors and communicate the death notification to the relative in their own words. In this exercise, the element of surprise was important for making the situation feel real.

After conveying initial information about the exercise, the students waited outside the classroom until it was their turn so that the setting would be as realistic as possible. The role play was performed without any audience and was filmed. When the students came into the room, the exercise started with the teacher in the role of next of kin waiting for their relative to return. The teacher, playing next of kin, pretended to be unaware that the husband or wife had died and asked about the relative. The exercise was interrupted when the students uttered the words "died" or "deceased."

The entire deliberation-the role-playing- took only a few minutes. Many students were moved by the exercise; some students were so affected that they had difficulty perceiving when the teacher ended the exercise and was no longer in character. The students in each group had an opportunity to reflect on their feelings while the subsequent student groups carried out their exercise. After all student groups had participated in the exercise, the entire cohort gathered for deliberation and reflection. The analysis phase began when video recordings of all exercises were played. 
While the videos were being played, it was possible to stop the recording and re-enact a continuation of the scene in the form of role-playing.

\section{Post-role play questionnaire}

After completion of the role play, a second questionnaire was administered which contained questions on how the students evaluated the communication technique skills and how they perceived role-play-giving and receiving feedback. The visual analogue scale (VAS), a straight line, $100 \mathrm{~mm}$ in length, anchored by word descriptions at end, was used to measure students' perspective of death notification. ${ }^{16}$ Students were asked to make a mark along the line, indicating their subjective perspective of death notification.

In this study, the VAS consisted of a multi-item scale. The first VAS, the response 'too low level, I already knew that' is assigned the value $0 \mathrm{~mm}$, 'difficult to follow what was said' the value $100 \mathrm{~mm}$. The second VAS, $0 \mathrm{~mm}$ is represented 'fairly irrelevant, I have little need of this with patients at my work' and $100 \mathrm{~mm}$ 'really relevant'. The third VAS has endpoints labelled 'no utility, what I learned I will probably not apply' and 'very useful, I will apply this daily', denoted as 0 and $100 \mathrm{~mm}$, respectively.

\section{Data Analysis}

The pre-role play and post-role play questionnaires were analyzed using quantitative content analysis as that method is suitable for describing the content of texts and communication in an objective and systematic manner. ${ }^{17-19}$ The analysis was performed in three steps. First, the responses from the open-ended questionnaires were gathered. Considering the context, the meaning units were condensed into a description close to the text and, where possible, into an interpretation of the underlying meaning, the latent content. Quantitative content analysis allowed for inclusion of large amounts of textual information and systematically identification of its properties, e.g. the frequencies by using descriptive statistics. The frequency analysis was made to ensure that "vivid but false impressions were not regarded as more meaningful and pervasive than otherwise might be inferred without such frequencies. ${ }^{20}$ Second, all of the responses to the open-ended questions were read and reread to extrapolate common themes. Finally, each concept or idea represented was labelled with a code and the similar codes were then clustered into sub-categories and later collapsed into categories. ${ }^{19}$ Descriptive statistics were used to describe the items of the VAS.

\section{Results}

Data analysis is divided into parts, the first presenting the content analysis of the open-ended questionnaires, and the second focuses on the descriptive analysis of the items on the VAS. The extracted subcategories units from the openended questionnaires were categorized into clusters of six central themes: communication, emotions, self- development, exercise-related, learning opportunities and tools and strategies and 44 subcategories (Table 1).

Below, each theme is discussed with quoted words and phrases from students to support authors' claims and illustrate ideas.

Table 1. The classification of categories and subcategories

\begin{tabular}{|c|c|}
\hline Categories & Subcategories \\
\hline Communication & $\begin{array}{l}\text { Improved communication } \\
\text { Conflicts/sensitive situations } \\
\text { Interplay with others } \\
\text { No effect }\end{array}$ \\
\hline Emotions & $\begin{array}{l}\text { Lack of efficiency } \\
\text { Tiring } \\
\text { Dissatisfaction } \\
\text { Contented } \\
\text { Content but want more } \\
\text { Passive } \\
\text { Uncertain }\end{array}$ \\
\hline Exercise-related & $\begin{array}{l}\text { Notify bad news } \\
\text { Give feedback } \\
\text { Interaction with others } \\
\text { Degree of difficulty } \\
\text { Sensitive topics } \\
\text { The playback feature } \\
\text { Act with unknown/actor } \\
\text { Time/more exercises } \\
\text { Alternative solutions to situations }\end{array}$ \\
\hline Learning opportunities & $\begin{array}{l}\text { Learning through feedback } \\
\text { Experience } \\
\text { Group size } \\
\text { Sharing experiences } \\
\text { Stimulate discussion } \\
\text { Inspire } \\
\text { Lead } \\
\text { Supportive }\end{array}$ \\
\hline Self-development & $\begin{array}{l}\text { Increased self-awareness } \\
\text { Self-confidence } \\
\text { Humble } \\
\text { Increased understanding of others } \\
\text { Reflection } \\
\text { Preparation } \\
\text { Development } \\
\text { Result-oriented } \\
\text { Deepened insight } \\
\text { Maturity } \\
\text { Security } \\
\text { Improved communication skills }\end{array}$ \\
\hline Tools and strategies & $\begin{array}{l}\text { Tips, tricks } \\
\text { Theory } \\
\text { Teacher contribution of experience } \\
\text { Tools, strategies }\end{array}$ \\
\hline
\end{tabular}

\section{Communication}

One important category was communication; the students expressed a need for it prior to the exercise, both as a general need for requiring skills in this area but also for special exercises focusing on different aspects of communication. The most commonly requested area that students desired experience was related to delicate situations or how to handle conflicts. The students recognized that the communication could be affected by uneven power in patientphysician relationships but also that people in crisis may have difficulties in understanding the information.

\footnotetext{
"Hopefully, it can lead to a good foundation for having difficult conversations in my early career as a physician before I have established my self-confidence and before I have my own experiences of talking about serious issues with patients"
} 
"I am mostly concerned about dealing with angry patients and also their relatives. I am not used to people getting angry or screaming at me. I want to be able to handle those internal feelings and at the same time be able to listen to what is behind the anger."

"Makes me more aware about how I interact with patients and their relatives."

\section{Emotions}

In the category Emotions, most students expressed that they were emotionally affected by the exercise, either in anticipation of the exercise or afterwards. Some found it tiring; most were very content with the exercise.

"It's going to be fun and instructive; I'm a little bit worried over the video playback."

\section{Self-development}

Self-development seemed to have been the most important desired outcome before the exercise and also was emphasized as an important learning outcome after the exercise. Traits that students wanted to gain or that they reflected on afterwards were increased self-awareness, self-confidence, humility, increased understanding of others, reflection, preparation for their professional life, deeper insight, maturity, a sense of security, and improved communication skills were reflected upon afterwards.

"We all had different ways of acting, and there is no right or wrong way. It all starts with oneself."

"I hope to develop myself as a fellow human being and also learn about myself-to try to understand how I react to the feelings of others."

\section{Learning opportunities}

The conditions for learning were also central, including learning from receiving, giving and listening to others receiving feedback, but also the sharing of experiences, having teachers who supported and led the group and stimulated discussion. Group size was a condition for learning.

"The teacher should help us to find the key message amidst all of the dialogue-contribute with their own experience, give tips and support."

\section{Tools and strategies}

To learn the theory on what builds good communication and to learn from others' experience, getting tips and tricks or tools and strategies that could be used to improve communication was sought after in advance and emphasized after the exercise.

"I learned the importance of different strategies for different situations."

\section{The marathon death exercise}

Different points of view relating to the exercise were explored. Prior to the exercise, the students wanted to practice delivering difficult news. They remarked on different aspects, such as the degree of difficulty in the exercise, the content of the exercise, such as wanting practice with sensitive topics, but also the form of the exercise (i.e., the playback moment for which there was anticipation for some students before the exercise but also after the exercise, it was found to increase the experience and learning outcome). Some students pointed to the delicate balance of using the playback versus not using it in regards to the time that was available. Another salient response was that students' desired to have the opportunity to act with someone they did not know or a professional actor.

"To use role play and video playback to emphasize good and less good behavior and conversation methodology. It provided an opportunity to reflect on whether there is more than one way that is right. Different strategies and approaches can be used."

\section{Questionnaire before the exercise}

The first questionnaire consisted of 5 open-ended questions asking about expectations before the exercise. The first open-ended question asked about what the students thought the exercises would mean to them as a future physician. Of the answers, $32.4 \%$ contained statements that the students perceived the exercise as a 'preparation' for their future occupation as physicians. Additionally, 25.7\% of the answers stated that they were hoping to get 'tools and strategies' to handle the tasks as a physician, while $18.9 \%$ were expecting to enhance their performance in different areas, such as 'communication'. Few students (14.9\%) thought that they would get to "reflect", and 5.4\% were expecting to 'see alternative ways of handling different situations'.

The second open-ended question asked the students how they thought the exercises would affect them as a human being. Some students (20.3\%) thought they would increase in 'maturity' and 'feel more secure'; $17.6 \%$ thought that it would have 'no effect' at all; $12.2 \%$ thought that it would give them increased 'self-awareness'; $12.2 \%$ hoped to be better at 'communication'; $6.8 \%$ thought it would give them an opportunity to 'reflect' and would provide a foundation for thought; $6.8 \%$ were 'uncertain' as to whether they would be influenced; and $1.4 \%$ of the answers indicated that students hoped for an increased understanding of others'.

The third open-ended question, on the role of the teachers, indicated that $55.4 \%$ wanted the role of teachers to be a leading, guiding and rule-providing role; $25.7 \%$ contained responses such as the teachers should be wise, share experiences, and inspire; $16 \%$ wanted the teachers to give feedback; $12.2 \%$ wanted the teachers to initiate stimulating discussions; $6.8 \%$ wanted tips and ideas, and $1.35 \%$ of the answers were of a passive nature.

On responding to the fourth open-ended question, 60.8 $\%$ students reported that they wanted to practice delivering bad news, such as death notifications; $28.4 \%$ wished to be 
trained in engaging in patient conversations regarding sensitive topics; $21.6 \%$ interested in receiving training on dealing with emotional patients or relatives and also to be trained in emotionally intense situations.

The final open-ended questions asked students about their attitudes towards the use of the retreat when the exercise occurs. The majority of students $(66.2 \%)$ had a positive attitude; $9.5 \%$ had a positive attitude but were nervous; $8.1 \%$ had no idea, and $4 \%$ had a negative attitude of the use of the retreat where the exercise took places.

\section{Questionnaire after the exercise}

Seventy-eight out of 86 students responded the VAS items and the second open-ended questionnaire, 53 women and 25 men. A minority of the students (9\%) did not take part in the study. The second open-ended questionnaire asked about the exercise and the marathon death. The first mean VAS item was $45 \mathrm{~mm}$, representing an optimal level of students' perspective of death notification. The second VAS item had a mean of $91 \mathrm{~mm}$, indicating the students valued the importance of communication skills in death notification. The third VAS has endpoints labelled 'no utility, what I learned I will probably not apply' and 'very useful, I will apply this daily', denoted as 0 and $100 \mathrm{~mm}$, respectively. The third mean VAS item was $81 \mathrm{~mm}$, confirming the importance of communication skills.

In the second open-ended questionnaire, the vast majority of students (97.4\%) reported that they had the opportunity to learn the conversation skills on the exercise. They also received a great "insight" (28.2\%) and obtained useful "tips and tricks" (20.5\%). Few students wished to "see alternative solutions to situations". Some students (37.2\%) reported to plan for "more exercises". However, 26.9\% of students felt that they do not need to learn anything. A minority of students wanted "professional actor to interact with", a high level of the exercises and "theory" to deliver the death notification, $3.8 \%, 2.6 \%$ and $1.3 \%$, respectively.

\section{Discussion}

The final service a doctor gives to his or her patients is to notify relatives of the death of the patient and to empathize with the relatives of patients. Delivering the notification of death is a difficult task for physicians. This may be attributed to the fact that little effort has been made to embed notification of death of a patient within the undergraduate medical education curriculum. For example, research studies show that a number of health care professionals have not received death notification training during medical school or residency programs. ${ }^{2,5}$

The lack of training in death notification is not excusable as there are data suggesting that it is a skill that can be trained. ${ }^{21}$ Research studies revealed the importance of educational programs for improving the physicians' ability to impart relatives of a patient's death. ${ }^{21}$ In our study, before embarking on the death notification exercise, the students reported that they need to practice distressing conversations, in particular the process of death notification. This could be due to the fact that medical students feel that they have not enough training to communicate death notifications. ${ }^{22-24}$ The students valued developing educational tools and strategies for delivering death notifications with an emphasis on improving communication skills. Few studies have investigated the effect of training in death notification. A large number of studies have shown that educational programs have improved students' experience, confidence and competence of death notification. ${ }^{9,11,25,26}$

After involving in the death notification role-play exercise, students valued the opportunity to learn how to complete the death notification process. The students also expressed the importance of having an opportunity to be trained in communication skills, particularly imparting death notifications before they are faced with communicating death notifications.

There are limitations to our study. First, the present sample was a convenience sample and hence its generalisiability is questionable. Second, with regards to our measurement of death notification, the VAS is self-reported. It measures students' perspectives of death notification and hence it is likely that students provided socially desirable responses. Lastly, although our study is limited to one school, we feel that the findings of our study can be transferred to medical schools that have a similar situation to ours.

\section{References}

1. Eth S, Baron DA, Pynoos RS. Death notification. Bull Am Acad Psychiatry Law. 1987;15:275-81.

2. Stewart AE, Lord JH, Mercer DL. A survey of professionals' training and experiences in delivering death notifications. Death Stud. 2000;24:611-31.

3. Ahrens WR, Hart RG. Emergency physicians' experience with pediatric death. Am J Emerg Med. 1997;15:642-3.

4. Stewart A. Complicated bereavement and posttraumatic stress disorder following fatal car crashes: Recommendations for death notification practice. Death Stud.1999;23:289-321.

5. Schmidt TA, Norton RL, Tolle SW. Sudden death in the ED: educating residents to compassionately inform families. J Emerg Med. 1992;10:643-7.

6. Phitayakorn R, Gelula MH, Malangoni MA. Surgical journal clubs: A bridge connecting experiential learning theory to clinical practice. J Am Coll Surg. 2007;204:158-63.

7. Bolan CM. Incorporating the experiential learning theory into the instructional design of online courses. Nurse Educ. 2003;28:10-4.

8. Kolb DA. Experiential learning. Experience as the source of learning and development. Englewood Cliffs, NJ: Prentice Hall; 1984.

9. Hobgood C, Harward D, Newton K, Davis W. The educational intervention "GRIEV_ING" improves the death 
notification skills of residents. Acad Emerg Med. 2005;12:296-301.

10. Smith-Cumberland TL, Feldman RH. Survey of EMTs' attitudes towards death. Prehosp Disaster Med. 2005;20:184-8.

11. Smith-Cumberland T. The evaluation of two death education programs for EMTs using the theory of planned behavior. Death Stud. 2006;30:637-47.

12. Boal A. Games for Actors and Non-Actors. London: Routledge; 1992.

13. Boal A. Legistlative Theatre. London: Routledge; 1998.

14. Boal A. Theatre of the Oppressed. London: Pluto Press; 2000.

15. Aycock N, Boyle D. Interventions to manage compassion fatigue in oncology nursing. Clin J Oncol Nurs. 2009;13:183-91.

16. Grant S, Aitchison T, Henderson E, Christie J, Zare S, McMurray J, et al. A comparison of the reproducibility and the sensitivity to change of visual analogue scales, Borg scales, and Likert scales in normal subjects during submaximal exercise. Chest. 1999;116:1208-17.

17. Polit D, Hungler B. Essentials of Resarch: Methods, appraisals and utilization. 4th edition ed. Philadelphia, Pennsylvaniia: Lippencott-Raven; 1997.

18. Waltz C, Strickland O, Lenz E. Measurement in nursing research. 2nd edition ed. Philadelphia, Pennsylvania1991. 19. Weber R. Basic content analysis. 2nd edition ed. Newbury Park, California: Sage Publications; 1990.

20. Eisenhardt KM, Schoonhoven CB. Organizational growth - Linking founding team, strategy, environment, and growth among United-States semiconductor ventures, 1978-1988. Admin Sci Quart. 1990;35:504-29.

21. Pollack M. Educating new resident physicians in death notification. Acad Med. 1999;74:721.

22. Gillard JH, Dent TH, Aarons EJ, Crimlisk HL, SmythPigott PJ, Nicholls MW. Preregistration house officers in the Thames regions: changes in quality of training after four years. BMJ. 1993;307:1176-9.

23. Rappaport W, Witzke D. Education about death and dying during the clinical years of medical school. Surgery. 1993;113:163-5.

24. Charlton R, Ford E. Education needs in palliative care. Fam Pract. 1995;12:70-4.

25. Smith-Cumberland TL, Feldman RH. EMTs' attitudes' toward death before and after a death education program. Prehosp Emerg Care. 2006;10:89-95.

26. Hobgood CD, Tamayo-Sarver JH, Hollar DW, Jr., Sawning S. Griev_Ing: death notification skills and applications for fourth-year medical students. Teach Learn Med. 2009;21:207-19. 